\title{
Comparison of Hand Grip Strength in Diabetics and Non-Diabetics-An Observational Study
}

\author{
Neha $\mathrm{M}^{1 *}$, Jitendra $\mathrm{L}^{2}$ and Lata $\mathrm{P}^{3}$ \\ ${ }^{1}$ College of Physiotherapy, Sumandeep Vidyapeeth, India \\ ${ }^{2}$ Department of Medicine, Smt. B.K. Shah Medical Institute and Research Center, \\ Sumandeep Vidyapeeth, India \\ ${ }^{3}$ College of Physiotherapy, Sumandeep Vidyapeeth, India
}

\section{Research Article \\ Volume 3 Issue 3}

Received Date: May 01, 2019

Published Date: May 31, 2019

DOI: $10.23880 /$ mjccs- 16000221

*Corresponding author: Neha Mukkamala, Assistant Professor, College of Physiotherapy, Sumandeep Vidyapeeth, Waghodiya-391760, Vadodara, Gujarat, India, Tel: +919898216184; Email: neha.cop@sumandeepvidyapeethdu.edu.in

\section{Abstract}

Background and objectives: The growing prevalence of Type II Diabetes mellitus (T2DM) in India, which is associated with high morbidity and mortality, poses a major public health challenge. An association between handgrip strength and the prevalence of T2DM could provide a lead for preventive interventions. Hand grip strength is a simple, non-invasive and low-cost measure of muscle strength and quality. The present study aimed at comparing the handgrip strength of subjects with and without T2DM.

Methods: Two hundred and eighty subjects, 150 having T2DM and 130 without diabetes were recruited and their handgrip strength was assessed in both the hands with a JAMAR dynamometer in the sitting position. An average of three readings was taken for both the hands.

Results: There was a significant difference $(p<0.05)$ between the handgrip strength of the two groups, with the diabetic group showing lower values. Males and females in both the groups also showed a significant difference $(p<0.05)$ in the handgrip strength. Also a significant inverse correlation was seen $(p<0.05)$ between age of diabetic subjects and handgrip strength and duration of diabetes and handgrip strength.

Conclusion: Handgrip strength values were found to be lower in subjects with T2DM than in those without diabetes. As the age and duration of diabetes increased, the handgrip strength decreased.

Keywords: Type II Diabetes Mellitus; Handgrip Strength; JAMAR Dynamometer

Abbreviations: T2DM: Type II Diabetes Mellitus; BMI: Body Mass Index; ADA: American Diabetes Association; IGT: Impaired Glucose Tolerance.

\section{Introduction}

India ranks second only to China worldwide, in the number of adults living with diabetes. According to the 


\section{Medical Journal of Clinical Trials \& Case Studies}

International Diabetes Federation, India's population of diabetics is set to increase from 69.2 million in 2015 to 123.5 million cases by 2040 . As Type 2 Diabetes Mellitus (T2DM) is associated with high morbidity and mortality, the expansion of this epidemic is a major public health challenge [1].

According to Park, et al. adults with diabetes exhibit less lower extremity skeletal muscle strength than nondiabetics and Diabetes Mellitus is associated with accelerated loss of leg muscle strength and quality [2]. Another study states that in subjects with diabetes there is reduced strength of ankle and knee muscles with strength preserved at the elbow and wrist compared to non-diabetics [3]. Many studies have evaluated the strength of lower extremities using isokinetic dynamometer, which is an expensive device and is not portable [4]. Handgrip strength, on the other hand, is a simple, non-invasive and low-cost measure of muscle strength and quality and may be useful in identifying people at risk of T2DM. Higher hand grip strength is associated with a lower risk of developing T2DM especially in lean individuals [2]. Evidence for an association between handgrip strength and the prevalence of type 2 diabetes could lead to preventive interventions [5]. Studies on the association of handgrip strength with T2DM are mostly on Hispanic, African American or Japanese American populations [2]. Even though Asian Indians have a higher risk of diabetes compared to other Asian populations, there is a dearth of evidence in Indian and South-Asian populations $[2,6]$. To our knowledge, very few studies have measured the handgrip strength in the Indian population of diabetics and compared it with non-diabetics. So the present study was undertaken to measure the handgrip strength in diabetics and non-diabetics and to see if any difference between the two existed.

\section{Materials and Methods}

The present study was a cross-sectional observational study conducted at our general hospital in Gujarat. The study was reviewed and approved by the institutional ethics committee and all subjects gave a written informed consent to participate.

\section{Inclusion Criteria}

Subjects with a diagnosis of T2DM and those not having diabetes were recruited for this study. All subjects were above 18 years of age and the sample included both males and females. Known or newly diagnosed cases of T2DM or those receiving oral hypoglycemic pills and/or insulin were included.

\section{Exclusion Criteria}

Those having type 1 diabetes, upper limb pain, trauma/fracture around the hand within the past year, a history of stroke, any intravenous lines on the hand, were excluded from the study.

\section{Methodology}

Two hundred and eighty subjects, one hundred and fifty with T2DM and one hundred and thirty without diabetes were recruited for the study from the medicine outpatient department as well as in-patient department at our hospital. T2DM was diagnosed according to American Diabetes Association (ADA) diagnostic criteria. Demographic data in the form of age, gender, occupation, hand dominance and body mass index (BMI) was collected from all the subjects. Other subjects coming to our hospital for treatment but who did not have diabetes were included in the non-diabetic group.

The hand dominance was determined by asking the patient the side with which he/she writes or the side with which he/she eats food. BMI was calculated as weight in kilograms divided by squaring the height in meters. For measuring the height, the patient was made to stand without shoes against a wall with the feet flat together against the wall, legs straight, arms at side and patient looking straight ahead, the line of sight being parallel to the floor. A scale was used till it firmly touched the crown of the head and a mark was made on the wall. Then a measure tape was used to measure from the base of the floor to the marked measurement on the wall to get the height measurement.

The handgrip strength of all the subjects was taken with JAMAR, hydraulic hand dynamometer (JAMAR, Sammons Preston, Rolyon, Bolingbrook, IL). Subjects were seated comfortably on a chair without armrests. The shoulder was abducted and neutrally rotated, with the elbow at $90^{\circ}$ flexion, and the forearm and wrist in a neutral position. A demonstration of maximum handgrip strength was given to each subject before they were asked to do it themselves. Verbal instructions to squeeze the handle as hard as possible were given prior to as well as during the measurements. The measurement for grip strength was taken with the handle in the second position. Three measurements of each grip were obtained at 15 


\section{Medical Journal of Clinical Trials \& Case Studies}

second intervals [7]. The dynamometer was reset to zero prior to each reading. All the subjects were tested on both the hands with the right hand first, irrespective of the hand dominance. The mean value of all the three readings for each hand was analyzed.

\section{Statistical Analysis}

Data was analysed using the IBM-SPSS version 20.0 software. The difference between the groups was evaluated using Mann-Whitney U test for nonparametric variables. Spearman's correlation analysis was used to find the association between two variables. The significance level was set at $\mathrm{p}<0.05$ for all tests.

\section{Results}

The study population consisted of 150 subjects with diabetes and 130 subjects without diabetes. The characteristics of the subjects are given in table 1 . In the diabetic group there were 77 females and 73 males. Out of 150 subjects, 138 were right hand dominant and 12 were left hand dominant. The mean duration of diabetes was 6.32 years ranging from newly diagnosed cases to duration of 40 years. In the non-diabetic group, there were 46 females and 84 males, and 103 were right hand dominant and 27 were left hand dominant. The mean age and BMI values of both the groups are as shown in table 1 .

\begin{tabular}{|c|c|c|c|}
\hline & Diabetics (n=150) & Non-diabetics (n=130) & p value \\
\hline Age (years) $($ Mean \pm SD) & $56.22 \pm 10.97$ & $50.3 \pm 11.49$ & $\mathrm{p}>0.05$ \\
\hline BMI $\left(\mathrm{kg} / \mathrm{m}^{2}\right)$ & $25.92 \pm 4.60$ & $23.93 \pm 4.22$ & $\mathrm{p}>0.05$ \\
\hline
\end{tabular}

Table 1: Characteristics of Subjects.

\begin{tabular}{|c|c|c|c|}
\hline Grip strength (kg) & $\begin{array}{c}\text { Diabetics (n=150) } \\
\text { (Mean } \pm \text { SD) }\end{array}$ & $\begin{array}{c}\text { Non-diabetics (n=130) } \\
\text { (Mean } \pm \text { SD) }\end{array}$ & p-value \\
\hline Right grip strength & $16.06 \pm 7.26$ & $20.58 \pm 8.04$ & $\mathrm{p}<0.001$ \\
\hline Left grip strength & $15.74 \pm 7.39$ & $20.15 \pm 7.92$ & $\mathrm{p}<0.001$ \\
\hline
\end{tabular}

Table 2: Comparison of hand grip strength (kg) values (mean \pm S.D.) of diabetic and non- diabetic subjects using MannWhitney U test.

\begin{tabular}{|c|c|c|c|}
\hline Grip strength $(\mathbf{k g})$ & $\begin{array}{c}\text { Males (n=157) } \\
\text { (Mean } \pm \text { SD) }\end{array}$ & $\begin{array}{c}\text { Females (n=123) } \\
\text { (Mean } \pm \text { SD) }\end{array}$ & p-value \\
\hline Right grip strength & $22.38 \pm 7.47$ & $12.78 \pm 4.60$ & $\mathrm{p}<0.001$ \\
\hline Left grip strength & $22.20 \pm 7.18$ & $12.15 \pm 4.60$ & $\mathrm{p}<0.001$ \\
\hline
\end{tabular}

Table 3: Comparison of hand grip strength $(\mathrm{kg})$ values (mean \pm S.D.) of males and females using Mann-Whitney U test.

\begin{tabular}{|c|c|c|c|c|c|c|}
\hline $\begin{array}{c}\text { Grip strength } \\
\text { (kg) }\end{array}$ & $\begin{array}{c}\text { Diabetic males } \\
\text { (n=73 ) } \\
\text { (Mean } \pm \text { SD) }\end{array}$ & $\begin{array}{c}\text { Non-diabetic males } \\
\text { (n=84 ) } \\
\text { (Mean } \pm \text { SD) }\end{array}$ & p-value & $\begin{array}{c}\text { Diabetic females } \\
\text { (n=77 ) } \\
\text { (Mean } \pm \text { SD) }\end{array}$ & $\begin{array}{c}\text { Non-diabetic females } \\
\text { (n=46 ) } \\
\text { (Mean } \pm \text { SD) }\end{array}$ & p-value \\
\hline Right grip strength & $20.27 \pm 7.14$ & $24.20 \pm 7.30$ & $\mathrm{p}<0.05$ & $12.18 \pm 4.59$ & $13.74 \pm 4.48$ & $\mathrm{p}<0.05$ \\
\hline $\begin{array}{c}\text { Left grip } \\
\text { Strength }\end{array}$ & $20.39 \pm 7.08$ & $23.77 \pm 6.93$ & $\mathrm{p}<0.05$ & $11.40 \pm 4.33$ & $13.36 \pm 4.82$ & $\mathrm{p}<0.05$ \\
\hline
\end{tabular}

Table 4: Comparison of hand grip strength of diabetic and non-diabetic males and females using Mann Whitney U test.

\begin{tabular}{|c|c|c|c|c|}
\hline & \multicolumn{2}{|c|}{ Diabetics } & \multicolumn{2}{c|}{ Non-diabetics } \\
\hline & Right grip strength & $\begin{array}{l}\text { Left grip } \\
\text { strength }\end{array}$ & Right grip strength & $\begin{array}{l}\text { Left grip } \\
\text { strength }\end{array}$ \\
\hline Spearman's correlation coefficient & -0.217 & -0.204 & -0.251 & -0.204 \\
\hline $\mathrm{p}$-value & $\mathrm{p}<0.05$ & $\mathrm{p}<0.05$ & $\mathrm{p}<0.05$ & $\mathrm{p}<0.05$ \\
\hline
\end{tabular}

Table 5: Correlation of age of diabetic and non-diabetic subjects with grip strength using Spearman's correlation coefficient. 


\section{Medical Journal of Clinical Trials \& Case Studies}

\begin{tabular}{|c|c|c|}
\hline & Right grip strength & Left grip strength \\
\hline Spearman's correlation coefficient & -0.249 & -0.202 \\
\hline $\mathrm{p}$-value & $\mathrm{p}<0.05$ & $\mathrm{p}<0.05$ \\
\hline
\end{tabular}

Table 6: Correlation of duration of diabetes with grip strength using Spearman's correlation coefficient.

\section{Discussion}

The present study was undertaken to study the differences in grip strength of 150 subjects with diabetes and 130 subjects without diabetes. An association has already been established between diabetes and lower skeletal muscle strength and quality. Grip strength is a marker for nutritional status, is positively and negatively related to normal bone mineral density in postmenopausal women and physical frailty respectively and is predictive of mortality due to cardiovascular diseases and cancer in men $[8,9]$.

The diabetic subjects, in the present study, had a significantly lower $(p<0.001)$ grip strength compared to the non-diabetic subjects (Table 2) [10]. According to several studies too, the diabetic group showed consistently lower grip strength compared to nondiabetics. E Cetinus, et al. in their study done on seventysix diabetics and forty-seven healthy volunteers without diabetes showed diabetics having average grip strength $(31.53 \pm 11.82 \mathrm{~kg})$ lower compared to non-diabetics $(36.34 \pm 11.01 \mathrm{~kg})[2,5,11-14]$. Savas $\mathrm{S}$, et al. evaluated 44 type 2 diabetic patients and 60 age and sex matched controls and found the grip and pinch strengths to be significantly lower in diabetic patients $(27.48 \pm 9.26 \mathrm{~kg})$ than the non-diabetic controls $(31.72 \pm 9.86 \mathrm{~kg})$ [12]. Sayer, et al. in their study on 1,391 men and women aged between 60-70 years found the mean grip strength in diabetic men to be $41.8 \mathrm{~kg}$ compared with $44.1 \mathrm{~kg}$ and $44.7 \mathrm{~kg}$ in men with impaired glucose tolerance (IGT) and normal glucose tolerance respectively.

In a study done on Indian population, the diabetic males and females had a lower grip strength compared to non-diabetics (diabetic males $=20.76 \pm 3.55 \mathrm{~kg}$ vs control males $32.90 \pm 7.60 \mathrm{~kg}$ ), (diabetic females $=18.36 \pm 3.50 \mathrm{~kg}$ vs control females $25.16 \pm 3.45 \mathrm{~kg}$ ) on the dominant side $[11,14]$. This can be attributed to a lesser muscle strength and quality in upper as well as lower extremities in diabetics even though their regional muscle masses were greater than those without diabetes. Cetinus, et al. attributed the lower values of hand grip strength to distal upper extremity flexor muscle weakness, which might be caused by the severity of neuropathy $[3,8]$. A study which evaluated muscular performance in subjects with type 2 diabetes and controls found subjects with diabetes to have muscle weakness at the ankle and knee, with preservation of strength at the elbow and wrist which is in contrast to the findings of the present study [13].

In the present study males had a significantly $(\mathrm{p}<0.05)$ higher grip strength than females in both the diabetic as well as the non-diabetic group (Tables $3 \& 4$ ) which is well in agreement with another study [4]. According to Westropp, et al. grip strength which is greater in males across all ages, peaks at 40 years after which it starts to decline for both genders $[8,10,13]$. In a study done to establish normative values of grip and pinch force of community dwelling elderly in the age group of 65-92, males were found to be stronger than females, but gender differences in forces decreased with age. Similarly, Ashu, et al. in their study on hand grip strength in community dwelling elderly in Gujarat also showed RGS to be 21.49 $\mathrm{kg}$ and $12.82 \mathrm{~kg}$ and LGS to be $20.47 \mathrm{~kg}$ and $11.99 \mathrm{~kg}$ in males and females respectively [15].

There was a significant inverse correlation between age and grip strength (Table 5$)$ in both the groups $(\mathrm{p}<0.05)$ suggesting that as age advanced the grip strength decreased in both groups [16]. This inverse correlation between age and grip strength is also supported by other studies. In a study done on elderly subjects above the age of 60 , also, there was a reduction in grip strength as age advanced $[13,15,16]$.

A significant inverse correlation was also seen between duration of diabetes and grip strength (Table 6) in both the hands $(\mathrm{p}<0.05)$ showing that as the duration of diabetes increased, the grip strength decreased [16]. This correlation is in line with the findings of a study done by Sayer, et al. in which known diabetes status was associated with significantly lower grip strength, particularly in men [11].

\section{Future Research and Clinical Implications}

Future researchers should consider if the results of this study translate across different ethnic groups, for people of different age ranges and other demographic variables. In addition, researchers should investigate the 


\section{Medical Journal of Clinical Trials \& Case Studies}

long term impact of grip strength reduction on other musculoskeletal issues within the human body. Also the reduction in grip strength to negatively affect the ability to use extremities for activities of daily living should be studied.

\section{References}

1. International Diabetes Federation atlas (2015) $7^{\text {th }}$ (Edn.).

2. Kooi AL, Snijder MB, Peters RJG, van Valkengoed IGM (2015) The Association of Handgrip Strength and Type 2 Diabetes Mellitus in Six Ethnic Groups: An Analysis of the HELIUS Study. PLoS ONE 10(9): e0137739.

3. Park SW, Goodpaster BH, Strotmeyer ES, Kuller LH, Broudeau R, et al. (2007) Accelerated Loss of Skeletal Muscle Strength in Older Adults with Type 2 Diabetes. The Health, Aging, and Body Composition Study. Diabetes Care 30(6): 1507-1512.

4. Andersen H, Nielsen S, Mogensen CE, Jakobsen J (2004) Muscle strength in Type 2 diabetes. Diabetes 53(6): 1543-1548.

5. Wander PL, Boyko EJ, Leonetti DL, McNeely MJ, Kahn SE, et al. (2011) Greater hand-grip strength predicts a lower risk of developing type 2 diabetes over 10 years in leaner Japanese Americans. Diabetes Res Clin Pract 92(2): 261-264.

6. Ramachandran A, Snehalatha C, Wan Ma RC (2014) Diabetes in South-East Asia: An update. Diabetes Res Clin Practice 103(2): 231-237.

7. Trampisch US, Franke J, Jedamzik N, Hinrichs T, Platen P (2012) Optimal Jamar Dynamometer Handle Position to Assess Maximal Isometric Hand Grip Strength in Epidemiological Studies. J Hand Surg 37(11): 2368-2373.

8. Park SW, Goodpaster BH, Strotmeyer ES, de Rekeneire N, Harris TB, et al. (2006) Decreased
Muscle Strength and Quality in Older Adults with Type 2 Diabetes. Diabetes 55(6): 1813-1818.

9. Norman K, Stobaus N, Gonzalez MC, Schulzke JD, Pirlich M (2011) Hand grip strength: outcome predictor and marker of nutritional status. Clinical Nutrition 30(2): 135-142.

10. Massy-Westropp NM, Gill TK, Taylor AW, Bohannon RW, Hill CL (2011) Hand Grip Strength: age and gender stratified normative data in a populationbased study. BMC Res Notes 4: 127.

11. Sayer AA, Dennison EM, Syddall HE, Gilbody HJ, Phillips DIW, et al. (2005) Type 2 Diabetes, Muscle Strength, and Impaired Physical Function-The tip of the iceberg? Diabetes Care 28 (10): 2541-2542.

12. Savas S, Koroglu BK, Koyuncuoglu HR, Uzar E, Celik H, et al. (2007) The effects of the diabetes related soft tissue hand lesions and the reduced hand strength on functional disability of hand in type 2 diabetic patients. Diabetes Res Clinical Prac 77(1): 77-83.

13. Cetinus E, Buyukbese MA, Uzel M, Ekerbicer $H$, Karaoguz A (2005) Hand grip strength in patients with type 2 diabetes mellitus.Diabetes Research and Clinical Practice 70(3): 278-286.

14. ParminderKaur SG, Ravneet S, Dimple, Anterpreet KA (2015) Hand grip strength in type 2 diabetics and non-diabetics. Pak J Physiol 11(3): 32-34.

15. Jansen CW, Niebuhr BR, Coussirat DJ, Hawthorne D, Moreno L, et al. (2008) Hand force of men and women over 65 years of age as measured by maximum pinch and grip force. J Aging and Phy Activity 16(1): 24-41.

16. Sharma A, Mukkamala N, Parmar L (2018) To establish normative data for hand grip strength amongst elderly. Nat J Integrated Res Med 9(6): 2327. 